\title{
Diary of an exam failure
}

\author{
Elizabeth Clifford
}

\section{December}

Should have noticed the portent of doom heralded by the fact that the results did not arrive in the post when everyone else's had. Should have noticed the warning signs when the man down the road knocked on the door holding a suspiciously fat-looking dog-eared envelope in his hand. Results delivered to the wrong address.

Devastated. Feel complete failure. Try in vain to find good reason why I should have falled (early dementia, slow growing tumour, transient global amnesia) but sadly cannot escape the fact that insufficient factual knowledge is to blame. Hang head in shame and return to work the next day to face the music. Self esteem at lowest ebb ever. Feel even incapable of writing out a drug chart because so obviously incompetent.

\begin{abstract}
January
January 1. New Year resolution to pass next time (although secretly still feel doomed to failure.) Start revision - every thing horribly familiar. Rising sense of panic not quashed by the purchase of the heaviest, and most expensive textbooks on the market. Examine self-hypnosis tapes on the neighbouring stand in the bookshop but none entitled 'How to pass the MRC Psych Part Two'. Anyway, can't afford them after forking out fee for sitting the exam again. Remember maternal proverb "good money always follows bad" with dismay. Spirits lift when revision group is formed by like-minded colleagues who also failed or want to avoid the pitfalls.
\end{abstract}

\section{February}

Solidly working for eight weeks and feel that at least the end ought to be in sight, but dismayed to find another eight weeks to go. Waste an inordinate amount of time talking to fellow sufferers about how little time is left and how much more there is to do, compared with only small amount of time actually doing it.

Recoll in horror whenever anyone tells you of another good book which must be read. According to current version of frequently revised timetable, have to read about 4000 pages of textbook each night in order to cover the syllabus. Feel helpless, then start to wonder about learned helplessness. Feel paranoid that the College is against you. Feel euphoric when manage to answer an MCQ without scoring negative marks. Feel strong urge to start acting out, but haven't got either time to go and buy razor blades, or money, due to panic buying of textbooks.

\section{March}

Life becomes associated with gradually increasing levels of subterranean panic. Increasing psychological distress caused by relentless passage of time towards the exam accompanied by sudden improvement in the weather, and urge to go out in the garden and peer at the bulbs and seeds to encourage them to grow. Conflict between relative distance of time to the Exam (at least another six unbearable weeks) with a desperate feeling that longer time is needed (only six weeks left).

\section{April}

On eve of much anticipated study leave, decide to phone College to check on entry. Insurmountable distress caused by their cool reply that, since they have not yet received back sponsorship form from clinical tutor - am not on the list to sit the exam! Panic-stricken and increasingly aggressive phone calls to all and sundry. Problem eventually resolved by extreme skill of tutor's secretary, who perceived significant risk of suicide from frantic phone calls. Week of study leave drags slowly. Make new revision plan for the rest of the week every day. Plan to read whole textbook a day, but by midweek feel impressed if even one chapter a day is completed. Develop significant number of complexes-obsessional cleaning, neurotic anxiety about pets' well-being, and depressive symptoms emerge with feeling of doom every breakfast and unbridled delight as bedtime approaches.

Eventually become carefree and laissez-faire. Just want to get the thing over and done with - 
even falling seems preferable to continued study at this stage.

\section{April 29: written papers}

Off down to London. Meet ashen faced colleagues in similar stage of fugue. Sit down in allocated place and realise from photo how dramatically appearance has changed since first sitting the Exam (i.e. older, more haggard). Turn over the Exam paper and attempt to remain conscious. None of the hotly predicted essay questions appear ... move on to short answers, and feel that have revised totally the wrong topics ... rush through the MCQs desperately looking for a question that is recognisable .... wonder whether to commit suicide before or after the Clinical.

\section{May 11: Clinicals}

Patient co-operative and helpful, but imagine examiners writing "FAIl" on the forms.

\section{June}

Go on holiday to miss the results. Despondent to see big fat envelope on the doormat and assume that it contains more re-application forms. Feel profoundly shocked to see that the College only want another sum of money to allow me to use the letters "MRC Psych" after my name...

Elizabeth Clifford, Registrar in Child and Adolescent Psychiatry, Wycombe

\section{There's a lot of it about}

\section{Tim Bleach}

Whenever patients summon a physician For painful symptoms or a weak condition The simple comfort of a definition That signals fever, spasm, dose, or bout, Relieves the burdened mind of high anxiety And labels illness with a due propriety (The patient still a part of broad society) For, really, there's a lot of it about.

Better to have angina or arthritis, Or piles or non-specific urethritis, Advanced tuberculosis or bronchitis, Bubonic plague or scrofula or gout, Than more mysterious maladies of mind Wherein the inner eye is rendered blind And highly-trained psychiatrists may find That, really, there's a lot of it about.
But when a man is mad and hyper-manic It tends to trigger off our latent panic Or make us sense such people as Satanic (Perhaps these things are better in than out); It frequently must seem a great deal easier If paranoia teams up with amnesia Whether in Spain or Scotland or Silesia For, really, there's a lot of it about.

If, for some reason, men become moronic Or make a weak response to purge or tonic Or simply sit in corners, catatonic. Or dance à la St Vitus with a shout, Whether the place is Balham or Belgravia They either need an expert or a saviour To rectify experience or behaviour For, really, there's a lot of it about. 